\title{
Collision-induced dissociation of aflatoxins
}

\begin{tabular}{|c|c|}
\hline Journal: & Rapid Communications in Mass Spectrometry \\
\hline Manuscript ID: & RCM-12-0460.R1 \\
\hline Wiley - Manuscript type: & Research Article \\
\hline Date Submitted by the Author: & 12-Nov-2012 \\
\hline Complete List of Authors: & $\begin{array}{l}\text { Kéki, Sándor; University of Debrecen, Applied Chemistry } \\
\text { Tóth, Katalin; University of Debrecen, Applied Chemistry } \\
\text { Nagy, Lajos; University of Debrecen, Applied Chemistry } \\
\text { Mándi, Attila; University of Debrecen, Organic chemistry } \\
\text { Kuki, Ákos; University of Debrecen, } \\
\text { Mézes, Miklós; Department of Nutrition, Szent István University, } \\
\text { Department of Nutrition } \\
\text { Zsuga, Miklós; University of Debrecen, Applied Chemistry }\end{array}$ \\
\hline Keywords: & $\begin{array}{l}\text { Aflatoxin, APCI-MS, collision-induced dissociation, fragmentation, } \\
\text { mycotoxin }\end{array}$ \\
\hline Abstract: & $\begin{array}{l}\text { RATIONALE: Aflatoxins, a type of mycotoxins particularly hazard to food } \\
\text { therefore, from analytical point of view, knowledge on their mass } \\
\text { spectrometric properties is essential. The aim of the present study was to } \\
\text { describe the collision-induced dissociation behavior of the four most } \\
\text { common aflatoxins including B1, B2, G1 and G2. The results of the present } \\
\text { investigation could be helpful in the mass spectrometric identification of } \\
\text { these aflatoxins from foods and feeds. } \\
\text { METHODS: Protonated aflatoxins were produced using atmospheric } \\
\text { pressure chemical ionization (APCI) mass spectrometry (MS) combined } \\
\text { with high-performance liquid chromatography (HPLC). For the MS/MS } \\
\text { experiments nitrogen was used as the collision gas and the collision } \\
\text { energies were varied in the range of } 9-40 \text { eV (in the laboratory frame). } \\
\text { RESULTS: The APCI-MS/MS measurements showed that the protonated } \\
\text { aflatoxins are relatively stable; their remarkable fragmentations occur at } \\
30 \text { eV collision energy. The main fragmentation channels were found to be } \\
\text { the losses of a series of carbon monoxide and loss of a methyl radical } \\
\text { which led to the formation of radical-type product ions. In addition, if the } \\
\text { aflatoxin molecule contained an ether- or lactone-oxygen atom linked to a } \\
\text { saturated carbon atom, loss of a water molecule was observed from the } \\
\text { precursor ion, especially in the case of aflatoxins G1 and G2. } \\
\text { CONCLUSIONS: A relatively small modification in the structure of aflatoxins } \\
\text { dramatically alters the fragmentation properties and this is particularly true } \\
\text { for aflatoxins B1 and B2. Due to the presence a C=C double bond } \\
\text { connected to the ether group in aflatoxin B1 no elimination of water was } \\
\text { observed but, instead, formation of radical-type product ions was } \\
\text { identified. Fragmentation of aflatoxin B1 yields the most abundant radical- } \\
\text { type cations, and this is in line with the well-known experience that among } \\
\text { the four aflatoxin derivatives substance B1 is the most dangerous to } \\
\text { health. }\end{array}$ \\
\hline
\end{tabular}




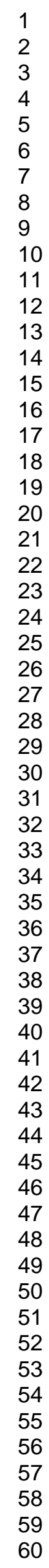

SCHOLARONE ${ }^{m}$

Manuscripts

http://mc.manuscriptcentral.com/rcm 


\title{
Collision-induced dissociation of aflatoxins
}

\author{
Katalin Tóth ${ }^{1}$, Lajos Nagy ${ }^{1}$, Attila Mándi ${ }^{3}$, Ákos Kuki ${ }^{1}$, Miklós Mézes ${ }^{2}$, Miklós Zsuga ${ }^{1}$, \\ Sándor Kéki ${ }^{1 *}$ \\ ${ }^{1}$ Department of Applied Chemistry, University of Debrecen \\ H-4032 Debrecen, Egyetem tér1., Hungary \\ ${ }^{2}$ Department of Nutrition, Szent István University \\ H-2103 Gödöllö, Péter Károly u. 1., Hungary \\ ${ }^{3}$ Department of Organic Chemistry, University of Debrecen, \\ H-4032 Debrecen, Egyetem tér1., Hungary \\ * Corresponding author: keki.sandor@,science.unideb.hu, fax: +36 52 518662; H-4032 \\ Debrecen, HUNGARY
}

RATIONALE: Aflatoxins, a type of mycotoxins particularly hazard to food therefore, from analytical point of view, knowledge on their mass spectrometric properties is essential. The aim of the present study was to describe the collision-induced dissociation behavior of the four most common aflatoxins including B1, B2, G1 and G2. The results of the present investigation could be helpful in the mass spectrometric identification of these aflatoxins from foods and feeds.

METHODS: Protonated aflatoxins were produced using atmospheric pressure chemical ionization (APCI) mass spectrometry (MS) combined with high-performance liquid chromatography (HPLC). For the MS/MS experiments nitrogen was used as the collision gas and the collision energies were varied in the range of 9-40 eV (in the laboratory frame).

RESULTS: The APCI-MS/MS measurements showed that the protonated aflatoxins are relatively stable; their remarkable fragmentations occur at $30 \mathrm{eV}$ collision energy. The main fragmentation channels were found to be the losses of a series of carbon monoxide and loss of a methyl radical which led to the formation of radical-type product ions. In addition, if the aflatoxin molecule contained an ether- or lactone-oxygen atom linked to a saturated carbon atom, loss of a water molecule was observed from the precursor ion, especially in the case of aflatoxins $\mathrm{G} 1$ and $\mathrm{G} 2$.

CONCLUSIONS: A relatively small modification in the structure of aflatoxins dramatically alters the fragmentation properties and this is particularly true for aflatoxins B1 and B2. Due 
to the presence a $\mathrm{C}=\mathrm{C}$ double bond connected to the ether group in aflatoxin $\mathrm{B} 1$ no elimination of water was observed but, instead, formation of radical-type product ions was identified. Fragmentation of aflatoxin B1 yields the most abundant radical-type cations, and this is in line with the well-known experience that among the four aflatoxin derivatives substance B1 is the most dangerous to health.

Keywords: Aflatoxin, APCI-MS, collision-induced dissociation, fragmentation, mycotoxin

\section{Introduction}

Mycotoxins attract more and more attention since getting into the human and animal nutrition these substances cause significant adverse health effects. Mycotoxins are mainly the secondary metabolites of fungal species. The WHO has acknowledged that contamination of food and feed with a variety of mycotoxins (such as aflatoxins, ochratoxin A, zearalenon, deoxynivalenol, fumonisin and T-2 toxin) is one of the major risk factors for the foodborne diseases ${ }^{1}$. Aflatoxins, a type of mycotoxins particularly hazard to food, carry a substituted coumarin-ring system. They are mainly the secondary metabolites of Aspergillus parasiticus and Aspergillus nominus fungi ${ }^{2}$. Of the aflatoxins, the B1, G1 and M1 7,8-dihydrofurano[2.3b]furan (DHFF) derivatives are highly toxic, while aflatoxins B2, G2 and M2 with a 2,3,7,8tetrahydrofurano[2.3-b]furan structure (THFF) are less toxic. Aflatoxin B1, occurring most commonly in foods ${ }^{3,4}$, shows high acute and chronic toxicity. In addition, the aflatoxins possess hepatotoxic, mutagenic, teratogenic and carcinogenic effects ${ }^{5-8}$. Correlation has also been established between the aflatoxin intake and liver cancer ${ }^{9,10}$.

Several instrumental methods have been developed for the fast and accurate determination of mycotoxins, both in the food and feed ${ }^{11-13}$. Depending on the type of mycotoxins various chromatographic methods have been applied for qualitative and quantitative determination ${ }^{14-}$ 19. However, with the appearance of soft ionization techniques such as APCI and ESI, application of LC/MS for the determination of mycotoxins has been increasing due to the high accuracy, sensitivity and selectivity of these mass spectrometric methods ${ }^{20-23}$.

In this article we report the detailed fragmentation study of four most common aflatoxins including aflatoxins B1, B2, G1 and G2. To our best knowledge no detailed report on the fragmentation properties and fragmentation pathways of this important and intriguing class of mycotoxins have been published. 


\section{Experimental}

\section{Chemicals}

All chemicals were purchased from Sigma Aldrich (Seelze, Germany). The standard mixture of aflatoxin containing B1, B2, G1 and G2 was dissolved in a mixture of methanol and water $(60: 40 \mathrm{v} / \mathrm{v})$. The concentration for B1 and G1 was $0.2 \mu \mathrm{g} / \mathrm{mL}$, and for B2 and G2 it was 0.06 $\mu \mathrm{g} / \mathrm{mL}$. The structures of the four aflatoxin derivatives investigated are presented in Scheme 1.

\section{Scheme 1.}

\section{Instrumentation}

High performance liquid chromatographic separation (HPLC)

The HPLC separation was performed with a Waters 2695 Separation module equipped with a Waters 2665 Diode Array Detector (Waters Milford, MA, USA) and coupled with a MicroTOF-Q mass spectrometer (Bruker Daltonik GmbH, Bremen, Germany). The separation was achieved with a Symmetry SB C18 reverse phase analytical column (4.6 x 150 mm, 3.5 $\mu \mathrm{m}$, Waters) at a $0.5 \mathrm{~mL} / \mathrm{min}$ flow rate, the column temperature was $35^{\circ} \mathrm{C}$. Isocratic method was performed with an eluent containing methanol and water (40:60 v/v). A $10 \mu \mathrm{L}$ standard aflatoxin solution was injected via a thermostable autosampler $\left(5^{\circ} \mathrm{C}\right)$.

\section{Atmospheric pressure chemical ionization quadrupole time-of-flight mass spectrometry (APCI-QTOF MS)}

The MS and MS/MS measurements were performed in the positive ion mode with a MicroTOF-Q type Qq-TOF mass spectrometer equipped with an APCI ion source (Bruker Daltonik GmbH, Bremen, Germany).

The source temperature of APCI was set to $390{ }^{\circ} \mathrm{C}$, the applied corona voltage was $5 \mathrm{kV}$. Nitrogen was used as nebuliser gas its pressure was 2 bar, the temperature of the drying gas $\left(\mathrm{N}_{2}\right)$ was kept at $200{ }^{\circ} \mathrm{C}$ and its flow rate was set to $6 \mathrm{~L} / \mathrm{min}$.

For the MS/MS experiments nitrogen was used as the collision gas and the collision energies were varied in the range of $9-40 \mathrm{eV}$ (in the laboratory frame). The pressure in the collision cell was determined to be $8 \times 10^{-3}$ mbar. The precursor ions for MS/MS were selected with an isolation width of $4 \mathrm{~m} / \mathrm{z}$ units. The MS/MS spectra were accumulated and recorded by means of a digitizer at a sampling rate of $2 \mathrm{GHz}$. The accuracy of the $m / z$ determination in the MS 
and MS/MS modes was within \pm 0.005 units. The mass spectra recorded were evaluated with the DataAnalysis 3.4 software from Bruker.

\section{Computational method}

Mixed torsional/low mode conformational searches were carried out for $6 \mathrm{a} R, 9 \mathrm{a} S$-aflatoxin $\mathrm{B} 1$ and the homochiral aflatoxins B2, G1 and G2 by means of the Macromodel 9.9.223 software using Merck Molecular Force Field (MMFF) in vacuo. ${ }^{24}$ The MMFF analysis provided 1, 2, 2 and 4 conformers in a $42 \mathrm{~kJ} / \mathrm{mol}$ energy window, respectively. All conformers were reoptimized at the B3LYP/6-31G(d), B3LYP/6-311G(d,p) and HF/6-31G(d) levels of theory implemented in the Gaussian 09 package. ${ }^{25}$ Electrostatic Potential (ESP) (Merz-Kollman) charges $^{26,27}$ were computed at all three levels. Protonated aflatoxins were built from the lowenergy B3LYP/6-31G(d) optimized conformers (in the case of carbonyl oxygens the protons were placed from inner and outer sides while in the case of ether and lacton oxygens the protons were placed in, above and below the plane) and optimized at the same level.

\section{Results and Discussion}

The separation of aflatoxins was achieved by high-performance liquid chromatography (HPLC) as detailed in the Experimental. In the APCI-MS/MS spectra of aflatoxins B1, B2, $\mathrm{G} 1$ and $\mathrm{G} 2$ only the protonated aflatoxin molecules $[\mathrm{M}+\mathrm{H}]^{+}$(precursor ions) occurred up to the collision energy of $20 \mathrm{eV}$ indicating the relatively stable structure of these derivatives. Fragmentation started only at higher collision energies. In Fig. 1. the survival yields (i.e., the fraction of undecomposed precursor ion) as a function of the collision energy for aflatoxins $\mathrm{B} 1, \mathrm{~B} 2, \mathrm{G} 1$ and $\mathrm{G} 2$ are plotted.

\section{Fig. 1.}

The survival yields of aflatoxins can be easily compared by using the collision energy necessary to obtain $50 \%$ fragmentation, i.e., the $\mathrm{CE}_{50}$ values. The $\mathrm{CE}_{50}$ values determined from the plot in Fig. 1. for B1, B2, G1 and G2 are $27.5 \mathrm{eV}, 30.7 \mathrm{eV}, 27.8 \mathrm{eV}$ and $30.1 \mathrm{eV}$, respectively. It is interesting that the $\mathrm{CE}_{50}$ values obtained for $\mathrm{B} 1$ and $\mathrm{G} 1$ are very similar (27.5 and $27.8 \mathrm{eV})$ and this is also true for aflatoxins B2 and G2 (30.7 and 30.1 eV). As a representative example the APCI-MS/MS spectrum of protonated aflatoxin B1 recorded at 38 $\mathrm{eV}$ is shown in Fig. 2. 
Fig. 2.

As seen in Fig. 2. several product ions appeared in the APCI-MS/MS spectra, which showed that the fragmentation of protonated aflatoxins is characterized by a series of carbonmonoxide loss. However, the fragmentation properties of the protonated aflatoxins B1 and B2 differ considerably from those of aflatoxins G1 and G2, thus it is appropriate to discuss them separately for the pairs (B1, B2) and (G1, G2).

\section{Fragmentation of protonated aflatoxins B1 and B2}

In the case of the protonated aflatoxins $\mathrm{B} 1$ and $\mathrm{B} 2$ the main fragmentation pathway is a consecutive losses of $\mathrm{CO}$ molecules from the precursor ion resulting in the formation of a series of product ions denoted by $[\mathrm{M}+\mathrm{H}-\mathrm{xCO}]^{+}$, where $\mathrm{x}$ is the number of the lost $\mathrm{CO}$ molecules. In the case of aflatoxins B1 and B2 CO losses with $\mathrm{x}$ up to 5 were observed. Interestingly, in addition to the product ions formed by $\mathrm{CO}$ losses $\mathrm{OE}^{\bullet+}(\mathrm{OE}$ means an oddelectron species) type product ions produced by the loss of a methyl radical with a composition corresponding to $\left[\mathrm{M}+\mathrm{H}-(\mathrm{CO})_{\mathrm{x}}-\mathrm{CH}_{3}\right]^{\bullet+}$ (where $\left.0 \leq \mathrm{x} \leq 5\right)$ can also be observed. The relative intensities of the product ions formed by losses of $\mathrm{CO}$ molecules together with that of the precursor ion are plotted in Fig. 3.a. For better visualization, the relative intensities are normalized and presented in Fig. 3.b.

Fig. 3.

Fig. 3a. and Fig. 3b. show that the maximum of intensities of the product ions formed by losses of CO molecules, i.e., those appeared at $m / z 285\left([\mathrm{M}+\mathrm{H}-\mathrm{CO}]^{+}\right), 257\left([\mathrm{M}+\mathrm{H}-2 \mathrm{CO}]^{+}\right)$, $229\left([\mathrm{M}+\mathrm{H}-3 \mathrm{CO}]^{+}\right), 201\left([\mathrm{M}+\mathrm{H}-4 \mathrm{CO}]^{+}\right)$and $173\left([\mathrm{M}+\mathrm{H}-5 \mathrm{CO}]^{+}\right)$are shifted gradually to higher collision energies indicating the consecutive formation of these product ions. In addition, parallel to $\mathrm{CO}$ molecule losses, elimination of a methyl radical also takes place. Fig. 3a. inset shows the relative intensities of the product ions at $\mathrm{m} / \mathrm{z} 285,257$ (formed from the ion $\mathrm{m} / \mathrm{z} 285$ by the loss of a CO molecule) and 270 (formed from the ion $\mathrm{m} / \mathrm{z} 285$ by the loss of a methyl radical) as a function of the collision energy. The curve for the $m / z 270$ ion shifted to higher collision energy as compared to that for the $\mathrm{m} / \mathrm{z} 257$ ion suggesting that elimination of a methyl radical requires higher activation energy than that of a $\mathrm{CO}$ molecule.

To determine the most probable sites for protonation of the aflatoxin molecules MerzKollman ESP charges were computed at 3 levels of theory for the low-energy reoptimized 
MMFF conformers obtained from mixed torsional/low mode conformational searches. According to the results, the oxygen atoms in aflatoxin $\mathrm{B} 1 \mathrm{can}$ be ordered as $\mathrm{O}(14) \approx \mathrm{O}(15)>$ $\mathrm{O}(10)>\mathrm{O}(6)>\mathrm{O}(7)>\mathrm{O}(12)$ where $\mathrm{O}(14)$ and $\mathrm{O}(15)$ bear the most negative partial charge (for a comparative table see Table S1. in the Supporting Information). This means that the first protonation occurs at $\mathrm{O}(14)$ and $\mathrm{O}(15)$ with the same probability. Optimizations of the protonated aflatoxin $\mathrm{B} 1$ showed that protonation at $\mathrm{O}(14)$ at the more probable outer site causes a slight elongation of $\mathrm{C}(11)-\mathrm{C}(11 \mathrm{a})$ bond while protonation of $\mathrm{O}(15)$ at the outer site has the same effect on the C(1)-C(11a) bond even in the optimized geometries (see Table S2. in the Supporting Information). This can indicate that in the case of protonation at $O(14)$ the CO cleavage takes place from the neighboring 6-membered ring and vice versa. Thus the first two $C O$ losses can be ascribed to $C(1)=O(14)$ and $C(11)=O(15)$.

The proposed fragmentation pathway for the aflatoxins B1 and B2 is depicted in Scheme 2: each product ion formed by the loss of a $\mathrm{CO}$ molecule can eliminate both the $\mathrm{CH}_{3}$ radical and a $\mathrm{C}_{2} \mathrm{H}_{4}$ unit. However, according to our study, only the loss of a $\mathrm{CO}$ molecule and a methyl radical from the precursor ion was seen directly, elimination of a $\mathrm{C}_{2} \mathrm{H}_{4}$ unit was observed neither in the case of aflatoxin B1 nor for aflatoxin B2.

\section{Scheme 2.}

In the case of Aflatoxin B2 we got similar order of the ESP charges of oxygen atoms; the only difference was that $\mathrm{O}(7)$ became more negative and surpassed $\mathrm{O}(6)$. This means that the probability of protonation at $\mathrm{O}(7)$ increased.

Besides the above mentioned two main fragmentation channels of aflatoxin B1 additional ones can also be observed. One of these is the elimination of $\mathrm{C}_{2} \mathrm{H}_{4}$ unit, which proceeds simultaneously with the $\mathrm{CO}$ elimination.

A zoomed APCI-MS/MS spectrum for the product ions appearing at $m / z 229$ is presented in Fig. 4.

\section{Fig. 4.}

Two peaks occur at $\mathrm{m} / \mathrm{z} 229$ and one of these corresponds to that formed by the elimination of a $\mathrm{CO}$ molecule, while the other is that produced by release of a $\mathrm{C}_{2} \mathrm{H}_{4}$ unit from the $m / z 257$ ion $\left([\mathrm{M}+\mathrm{H}-2 \mathrm{CO}]^{+}\right)$. This is confirmed by accurate mass measurement: the measured and calculated masses for the $[\mathrm{M}+\mathrm{H}-3 \mathrm{CO}]^{+}$ion $(257-\mathrm{CO})$ are 229.082 and 229.086, respectively, 
while these values for the $\left[\mathrm{M}+\mathrm{H}-2 \mathrm{CO}-\mathrm{C}_{2} \mathrm{H}_{4}\right]^{+}$ion $\left(257-\mathrm{C}_{2} \mathrm{H}_{4}\right)$ are 229.047 and 229.050, respectively.

The product ions formed by the release of a $\mathrm{C}_{2} \mathrm{H}_{4}$ unit occur with low intensity besides the product ions produced by the $\mathrm{CO}$ elimination in the case of aflatoxins B1 and B2.

Moreover, in the case of aflatoxin B2 the extent of $\mathrm{C}_{2} \mathrm{H}_{4}$ elimination is significantly higher than in the case of B1. Although in both aflatoxins B1 and B2 elimination of $\mathrm{C}_{2} \mathrm{H}_{4}$ is conceivable from ring $\mathrm{E}$, in the case of $\mathrm{B} 2$ there is an another possible site of loss in ring $\mathrm{A}$. According to the increased negativity of $\mathrm{O}(7)$ it is likely that the rupture of the $\mathrm{C}(8)-\mathrm{C}(9)$ bonds can contribute to the elimination of the $\mathrm{C}_{2} \mathrm{H}_{4}$ unit in aflatoxin B2. Fig. 4. inset shows the relative intensities of the product ions formed by $\mathrm{CO}$ and $\mathrm{C}_{2} \mathrm{H}_{4}$ eliminations from aflatoxin B1 as a function of the collision energy. As it turns out from Fig. 4. inset, the elimination of $\mathrm{CO}$ is favored over that of the $\mathrm{C}_{2} \mathrm{H}_{4}$ unit at all collision energies.

Furthermore, the release of a $\mathrm{C}_{2} \mathrm{H}_{2} \mathrm{O}$ unit from aflatoxin $\mathrm{B} 1$ and elimination of a $\mathrm{C}_{2} \mathrm{H}_{4} \mathrm{O}$ unit from aflatoxin B2 were found. The formation of these product ions may be the result of the cleavages taking place at the $\mathrm{C}(9)-\mathrm{C}(9 \mathrm{a})$ and $\mathrm{O}(7)-\mathrm{C}(6 \mathrm{a})$ bonds. The elimination of $\mathrm{C}_{2} \mathrm{H}_{2} \mathrm{O}$ and $\mathrm{C}_{2} \mathrm{H}_{4} \mathrm{O}$ units directly from the precursor ion proceeds only to a small extent. Moreover, at higher collision energies the CO-loss product ions further decompose by the rupture of their dihydrofuran ring resulting in the elimination of $\mathrm{C}_{2} \mathrm{H}_{2} \mathrm{O}$ and $\mathrm{C}_{2} \mathrm{H}_{4} \mathrm{O}$ units as shown in Scheme 2 for the aflatoxin B1 (product ions with $m / z$ 243, 215 and 187). Interestingly, elimination of a CHO radical can also be observed for both aflatoxins B1 and B2. For example, the product ion at $m / z 241$ presented in Fig. 2. is most probably formed from the $m / z 270$ ion by elimination of a CHO radical. Although as mentioned earlier, the fragmentation pattern of B2 is very similar to that of aflatoxin B1, an another difference between them besides the elimination of $\mathrm{C}_{2} \mathrm{H}_{4}$ is the considerable water-loss from the precursor ion in the case of $\mathrm{B} 2$. Elimination of a $\mathrm{H}_{2} \mathrm{O}$ molecule from the protonated aflatoxin $\mathrm{B} 1$ was not observed. Since the only structural difference between B1 and B2 is the presence of a double bond between the $\mathrm{C}(8)$ and $\mathrm{C}(9)$ atoms in $\mathrm{B} 1$, it is reasonable to assume that the oxygen atom connected to $\mathrm{C}(6 \mathrm{a})$ is eliminated in form of $\mathrm{H}_{2} \mathrm{O}$. The enhanced ESP charge of $\mathrm{O}(7)$ in $\mathrm{B} 2$ compared to $\mathrm{B} 1$ and the highly elongated $\mathrm{C}(6 \mathrm{a})-\mathrm{O}(7)$ bond in the optimized geometries can confirm this assumption. The possible reason for the difference manifesting in $\mathrm{H}_{2} \mathrm{O}$ elimination is outlined in Scheme 3.

\section{Scheme 3.}


According to Scheme 3, protonation of aflatoxin B2 at the $\mathrm{O}(7)$ followed by bond cleavage may take place yielding a primary alcohol from which $\mathrm{H}_{2} \mathrm{O}$ can eliminate.

\section{Fragmentation of aflatoxins G1 and G2}

In the case of aflatoxins $\mathrm{G} 1$ and $\mathrm{G} 2$ the elimination of a $\mathrm{H}_{2} \mathrm{O}$ molecule is the main fragmentation channel. The APCI-MS/MS spectrum of aflatoxin recorded at $32 \mathrm{eV}$ collision energy is shown in Fig. 5.

\section{Fig. 5.}

Taking into account that elimination of water from aflatoxin B1 was not observed at all, and water-loss occurred only to a small extent from aflatoxin B2, it is assumed that the extensive water-loss from aflatoxins G1 and G2 is due to the presence of the lactone ring. Thus, protonation at the oxygen atom of the lactone ring followed by $\sigma$-bond cleavage leads to the elimination of a water molecule as depicted in Scheme 4. Similarly to aflatoxins B1 and B2 Merz-Kollman ESP charges were computed for G1 and G2. According to the results the most negative partial charges are located on the oxygen atoms $\mathrm{O}(15), \mathrm{O}(16)$ and $\mathrm{O}(2)$ being $\mathrm{O}(15)$ only marginally more negative than the two others. This means that in contrast to aflatoxins B1 and B2 now we have three highly favored protonation sites (see Table S1. in the Suppoting Information). The protonation at $\mathrm{O}(2)$ resulted in the cleavage of $\mathrm{C}(1)-\mathrm{O}(2)$ even in the optimized geometries (see Table S2. in the Suppoting Information).

\section{Scheme 4.}

The resulting water-loss product ion can further decompose by elimination of a $\mathrm{C}_{3} \mathrm{O}_{2}$ or a $\mathrm{CO}$ unit. Fig.6. shows the relative intensity of the product ion formed by elimination of a water molecule $\left(\left[\mathrm{M}+\mathrm{H}-\mathrm{H}_{2} \mathrm{O}\right]^{+}\right)$and that of the $\left[\mathrm{M}+\mathrm{H}-\mathrm{H}_{2} \mathrm{O}-\mathrm{CO}\right]^{+}$and $\left[\mathrm{M}+\mathrm{H}-\mathrm{H}_{2} \mathrm{O}-\mathrm{C}_{3} \mathrm{O}_{2}\right]^{+}$ions.

\section{Fig. 6.}

Fig. 6. shows that elimination of water from the precursor ion starts at ca. $15 \mathrm{eV}$. Furthermore, it is also evident from Fig. 5. that ejections of $\mathrm{CO}$ and a $\mathrm{C}_{3} \mathrm{O}_{2}$ unit from the $\left[\mathrm{M}+\mathrm{H}-\mathrm{H}_{2} \mathrm{O}\right]^{+}$ion occurs nearly at the same collision energy (ca. $20 \mathrm{eV}$ ). However, the relative intensity of the $\left[\mathrm{M}+\mathrm{H}-\mathrm{H}_{2} \mathrm{O}-\mathrm{CO}\right]^{+}$ion at higher collision energies is significantly lower than that of the $[\mathrm{M}+\mathrm{H}-$ 
$\left.\mathrm{H}_{2} \mathrm{O}-\mathrm{C}_{3} \mathrm{O}_{2}\right]^{+}$ion indicating the higher stability of the latter. The higher stability of the $[\mathrm{M}+\mathrm{H}-$ $\left.\mathrm{H}_{2} \mathrm{O}-\mathrm{C}_{3} \mathrm{O}_{2}\right]^{+}$ion with respect to that of $\left[\mathrm{M}+\mathrm{H}-\mathrm{H}_{2} \mathrm{O}-\mathrm{CO}\right]^{+}$ion can be explained by the fragmentation channel presented in Scheme 4. Accordingly, elimination of a $\mathrm{C}_{3} \mathrm{O}_{2}$ unit from the $\left[\mathrm{M}+\mathrm{H}-\mathrm{H}_{2} \mathrm{O}\right]^{+}$ion leads to the formation of a relatively stable aromatic benzopyrylium cation.

The elimination of a $\mathrm{CO}$ molecule directly from the precursor ion also occurred in the case of aflatoxins $\mathrm{G} 1$ and $\mathrm{G} 2$, and the $[\mathrm{M}+\mathrm{H}-\mathrm{CO}]^{+}$ion further decomposed by a series of elimination of $\mathrm{CO}$ and $\mathrm{C}_{2} \mathrm{H}_{4}$ molecules. Moreover, this fragmentation channel is less significant in the case of aflatoxins G1 and G2 than with aflatoxins B1 and B2. In addition, the elimination of a methyl radical from the protonated aflatoxins G1 and G2 leading to the formation of radical cations, occurred only in a very vanishing extent. These observations indicate that protonation of the ether- or lactone-oxygen atom connected to saturated $\mathrm{C}-\mathrm{C}$ bonds opens a low activation energy fragmentation channel which is dominant over the radical ones with high activation energies.

\section{Conclusion}

The fragmentation properties of four aflatoxins including B1, B2, G1 and G2 were studied by energy-variable tandem mass spectrometry. The MS/MS results show that the main fragmentation channels of the investigated aflatoxins are accompanied by the losses of $\mathrm{CO}$, $\mathrm{H}_{2} \mathrm{O}$ and $\mathrm{CH}_{3}$ radical. It is shown that a relatively small modification in the structure of aflatoxins dramatically alters the fragmentation properties and this is particularly true for aflatoxins B1 and B2. Due to the presence a $\mathrm{C}=\mathrm{C}$ double bond connected to the ether group in aflatoxin B1 no elimination of water was observed but, instead, formation of radical-type product ions was identified. On the contrary, in the case of aflatoxin B2 one of the main fragmentation channels was the elimination of a water molecule, while the presence of radical-type product ions in the MS/MS spectra was not significant. Most probably due to the presence of a lactone ring in aflatoxins G1 and G2, the product ions were formed by the elimination of a $\mathrm{H}_{2} \mathrm{O}$ molecule from the precursor ion. These product ions occurred in a significant extent, while the radical-type cations appeared only with low relative intensity in the APCI-MS/MS spectra. Moreover, sequential losses of CO molecules were observed for all of the studied aflatoxin derivatives. Interestingly, fragmentation of aflatoxin B1 yields the most abundant radical-type cations, and this is in line with the well-known experience that among the four aflatoxin derivatives substance B1 is the most dangerous to health. 


\section{Supporting Information}

Additional supporting information (Merz-Kollman ESP charges, selected bond length values and Cartesian coordinates of the optimized structures) can be found in the online version of this article.

\section{Acknowledgement}

This work was financially supported by the grants K-101850 given by OTKA (National Found for Scientific Research Development, Hungary), TAMOP 4.2.1./B-09/1/KONV-20100007 and TAMOP-4.2.2/B-10/1-2010-0024. A.M. thanks the National Information Infrastructure Development Institute (NIIFI 10038), and Dr. T. Kurtán and Dr. I. Komáromi for the helpful discussion in the field of organic chemistry and molecular modeling. 


\section{References}

[1] WHO Food Additives Series 47: Safety evaluation of certain mycotoxins in food, FAO Food and Nutrition Paper 74, WHO: Geneva, 2001.

[2] W.O. Ellis, J.P. Smith, B.K. Simpson, J.H. Oldham. Aflatoxins in Food - Occurrence, Biosynthesis, Effects on Organisms, Detection, and Methods of Control. Critical Reviews in Food Science and Nutrition 1991, 30, 403.

[3] M.J. Sweeney, A.D.-W. Dobson. Mycotoxin production by Aspergillus, Fusarium and Penicillium species. Int. J. Food Microbiol. 1998, 43, 141.

[4] O.M. Moss. Risk assessment for aflatoxins in foodstuffs. Int. Biodeter. Biodegr. 2002, $50,137$.

[5] J.H. Williams, T.D. Phillips, P.E. Jolly, J.K. Stiles, C.M. Jolly, D. Aggarwal. Human aflatoxicosis in developing countries: a review of toxicology, exposure, potential health consequences, and interventions. Am. J. Clin. Nutr. 2004, 80, 1106.

[6] H.S. Hussein, J.M. Brasel. Toxicity, metabolism, and impact of mycotoxins on humans and animals. Toxicology 2001, 167, 101.

[7] T.E Massey, R.K. Srewart, J.M. Daniels, L. Ling. Biochemical and molecular aspects of mammalian susceptibility aflatoxin B1 carcinogenicity. Proceed. Sot. Exp. Biol. Med. 1995, 208, 213.

[8] M.A. Abdel-Wahhab, S.E. Aly. Antioxidants and radical scavenging properties of vegetable extracts in rats fed aflatoxin-contaminated diet. J. Agric. Food Chem. 2003, $51,2409$.

[9] A. Bintvihok, K. Wisutharom, D. Somboonchit, O. Triwutranon, S. Sutherat, S. Punmamuang, S. Wongsuthawads, L. Laurdkanwijai. Aflatoxin $\mathrm{B}_{1}$ residues in tissues of ducklings given feed containing aflatoxin and ammonium carbonate or propionic acid. Thai. J. Toxicol. 1987, 3, 31 .

[10] A. Bintvihok, K. Wisutharom, O. Triwutranon, P. Nualsritong, D. Somboonchit, S. Punmamuang. Transmission of aflatoxinB1 into eggs of laying hens fed aflatoxin B1 contaminated diets with polyvinyl pyrolidone and/or diatomaceous earth. Thai. J. Toxicol. 1987, 3, 40 .

[11] L.M. Lin, J. Zhang, P. Wang, Y.S. Wang, J.P. Chen. Thin-layer chromatography of mycotoxins and comparison with other chromatographic methods. J. Chromatogr. A. 1998, 815,3 .

[12] Y. Nonaka, K. Saito, N. Hanioka, S. Narimatsu, H. Kataoka. Determination of aflatoxins in food samples by automated on-line in-tube solid-phase microextraction coupled with liquid chromatography-mass spectrometry. J. Chromatogr. A. 2009, $1216,4416$. 
[13] C. Cavaliere, P. Foglia, C. Guarino, F. Marzioni, M. Nazzari, R. Samperi, A. Lagana. Aflatoxin M1 determination in cheese by liquid chromatography-tandem mass spectrometry. J. Chromatogr. A. 2006, 1135, 135.

[14] W. Langseth, T. Rundberget. Instrumental methods for determination of nonmacrocyclic trichothecenes in cereals, foodstuffs and cultures. J. Chromatogr. A. 1998, 815, 103.

[15] R. Krska, S. Baumgartner, R. Josephs. The state-of-the-art in the analysis of type-A and -B trichothecene mycotoxins in cereals. Fresenius J. Anal. Chem. 2001, 371, 285.

[16] R. Krska, R. Josephs. The state-of-the-art in the analysis of estrogenic mycotoxins in cereals. Fresenius J. Anal. Chem. 2001, 369, 469.

[17] H. Valenta. Chromatographic methods for the determination of ochratoxin A in animal and human tissues and fluids. J. Chromatogr. A. 1998, 815, 75.

[18] G.S. Shephard. Chromatographic determination of the fumonisin mycotoxins. J. Chromatogr. A. 1998, 815, 31.

[19] J.G. Wilkes, J.B. Sutherland. Sample preparation and high-resolution separation of mycotoxins possessing carboxyl groups. J. Chromatogr. B. 1998, 717, 135.

[20] P. Zöllner, B. Mayer-Helm. Trace mycotoxin analysis in complex biological and food matrices by liquid chromatography-atmospheric pressure ionisation mass specrometry. J. Chromatogr. A. 2006, 1136, 123.

[21] M. Careri, F. Bianchi, C. Corradini. Recent advances in the application of mass spectrometry in food-related analysis. J. Chromatogr. A. 2002, 970, 3.

[22] A. Di Corcia, M. Nazzari. Liquid chromatographic-mass spectrometric methods for analyzing antibiotic and antibacterial agents in animal food products. J. Chromatogr. A. 2002, 972, 53.

[23] W. Li, T.J. Herrman, S.Y. Dai. Determination of aflatoxin sin animal feeds by liquid chromatography/tandem mass spectrometry with isotope dilution. Rapid Commun. Mass Spectrom. 2011, 1222, 25.

[24] MacroModel; Schro $\square$ dinger LLC, 2012:

http://www.schrodinger.com/Products/macromodel.html.

[25] M.J. Frisch, G.W. Trucks, H.B. Schlegel, G.E. Scuseria, M.A. Robb, J.R. Cheeseman, G. Scalmani, V. Barone, B. Mennucci, G.A. Petersson, H. Nakatsuji, M. Caricato, X. Li, H.P. Hratchian, A.F. Izmaylov, J. Bloino, G. Zheng, J.L. Sonnenberg, M. Hada, M. Ehara, K. Toyota, R. Fukuda, J. Hasegawa, M. Ishida, T. Nakajima, Y. Honda, O. Kitao, H. Nakai, T. Vreven, J.A. Montgomery Jr., J.E. Peralta, F. Ogliaro, M. Bearpark, J.J. Heyd, E. Brothers, K.N. Kudin, V.N. Staroverov, T. Keith, R. Kobayashi, J. Normand, K. Raghavachari, A. Rendell, J.C. Burant, S.S. Iyengar, J. Tomasi, M. Cossi, N. Rega, J.M. Millam, M. Klene, J.E. Knox, J.B. Cross, V. Bakken, C. Adamo, J. Jaramillo, R. Gomperts, R.E. Stratmann, O. Yazyev, A.J. Austin, R. Cammi, C. Pomelli, J.W. Ochterski, R.L. Martin, K. Morokuma, 
V.G. Zakrzewski, G.A. Voth, P. Salvador, J.J. Dannenberg, S. Dapprich, A.D. Daniels, O. Farkas, J.B. Foresman, J.V. Ortiz, J. Cioslowski, D.J. Fox, Gaussian 09, Revision B.01, Gaussian Inc., Wallingford CT. 2010.

[26] U.C. Singh, P.A. Kollman. An approach to computing electrostatic charges for molecules. J. Comput. Chem. 1984, 5, 129.

[27] B.H. Besler, K.M. Merz Jr., P.A. Kollman. Atomic charges derived from semiempirical methods. J. Comput. Chem. 1990, 11, 431. 


\title{
Legends for the Schemes and Figures
}

\author{
Scheme 1. \\ The structures of the investigated aflatoxin derivatives.
}

\section{Scheme 2.}

Proposed fragmentation pathway for the protonated aflatoxin B1. The numbers below the compositions represent the calculated (upper) and the measured (lower) masses.

\section{Scheme 3.}

Proposed fragmentation mechanism for the elimination of a $\mathrm{H}_{2} \mathrm{O}$ molecule for protonated aflatoxin B2.

\section{Scheme 4.}

Proposed fragmentation mechanism for the eliminations of $\mathrm{H}_{2} \mathrm{O}$ and $\mathrm{C}_{3} \mathrm{O}_{2}$ units from protonated aflatoxin $\mathrm{G} 1$ and $\mathrm{G} 2$.

\section{Figure 1.}

Survival yield (SY) versus collision energy curves for the protonated aflatoxin B1, B2, G1 and G2.

\section{Figure 2.}

APCI-MS/MS spectrum of protonated aflatoxin B1 recorded at $38 \mathrm{eV}$ collision energy.

\section{Figure 3.}

(a) Variation of the relative intensities of the precursor ion and product ions formed by consecutive losses of $\mathrm{CO}$ molecules as a function of the collision energy in the case of protonated aflatoxin B1: $[\mathrm{M}+\mathrm{H}-\mathrm{CO}]^{+}(\mathrm{m} / z \text { 285), [M+H-2CO }]^{+}(\mathrm{m} / z \text { 257), [M+H-3CO}]^{+}(\mathrm{m} / z$ 229), $[\mathrm{M}+\mathrm{H}-4 \mathrm{CO}]^{+}(\mathrm{m} / \mathrm{z} 201),[\mathrm{M}+\mathrm{H}-5 \mathrm{CO}]^{+}(\mathrm{m} / \mathrm{z}$ 173). Figure inset shows the relative intensity versus collision energy curves for the product ions $[\mathrm{M}+\mathrm{H}-\mathrm{CO}]^{+}(m / z 285),\left[\mathrm{M}+\mathrm{H}-\mathrm{CO}-\mathrm{CH}_{3}\right]^{+}\left(\mathrm{m} / z\right.$ 270) and $[\mathrm{M}+\mathrm{H}-2 \mathrm{CO}]^{+}(\mathrm{m} / z 257)$.

(b) The normalized relative intensities versus collision energy for the product ions formed by consecutive losses of CO molecules. 


\section{Figure 4.}

The zoomed MS/MS spectrum of protonated aflatoxin B1 at around $m / z 229$ at $38 \mathrm{eV}$ collision energy. The inset shows the relative intensity versus collision energy curves for the product ions $m / z 257\left([\mathrm{M}+\mathrm{H}-2 \mathrm{CO}]^{+}\right),[\mathrm{M}+\mathrm{H}-3 \mathrm{CO}]^{+}(257-\mathrm{CO})$ and $\left[\mathrm{M}+\mathrm{H}-2 \mathrm{CO}-\mathrm{C}_{2} \mathrm{H}_{4}\right]^{+}(257-$ $\left.\mathrm{C}_{2} \mathrm{H}_{4}\right)$.

\section{Figure 5.}

MS/MS spectrum of protonated aflatoxin G1 recorded at $32 \mathrm{eV}$ collision energy.

\section{Figure 6.}

The variation of the relative intensities for the product ions $\left[\mathrm{M}+\mathrm{H}_{-} \mathrm{H}_{2} \mathrm{O}\right]^{+}(\mathrm{m} / z$ 311), $[\mathrm{M}+\mathrm{H}-$ $\left.\mathrm{H}_{2} \mathrm{O}-\mathrm{CO}\right]^{+}(\mathrm{m} / z 283)$ and $\left[\mathrm{M}+\mathrm{H}-\mathrm{H}_{2} \mathrm{O}-\mathrm{C}_{3} \mathrm{O}_{2}\right]^{+}(\mathrm{m} / z 243)$ as a function of the collision energy in the case of aflatoxin G1. 


\section{Scheme 1.}

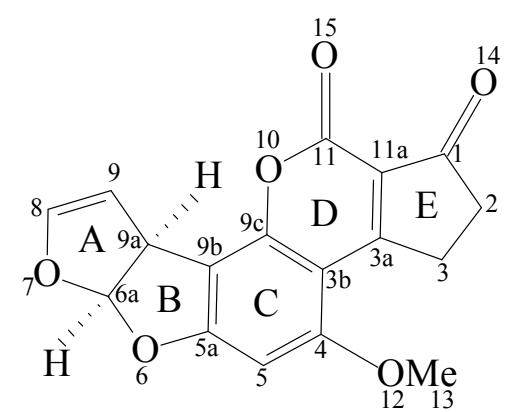

Aflatoxin B1

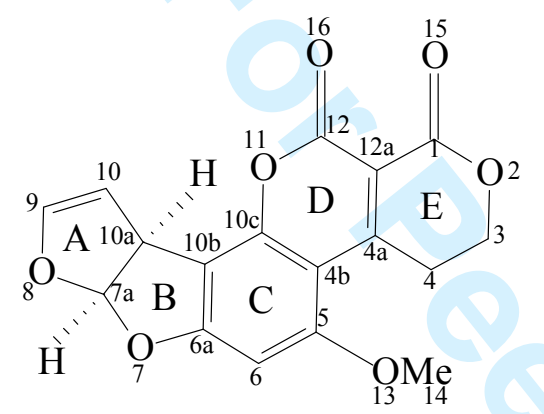

Aflatoxin G1<smiles>COc1cc2c(c3oc(=O)c4c(c13)CCC4=O)[C@H]1CCO[C@@H]1O2</smiles>

Aflatoxin B2<smiles>COc1cc(O[C@@H]2CCCO2)cc2oc(=O)c3c(c12)CCOC3=O</smiles>

Aflatoxin G2 
Scheme 2.

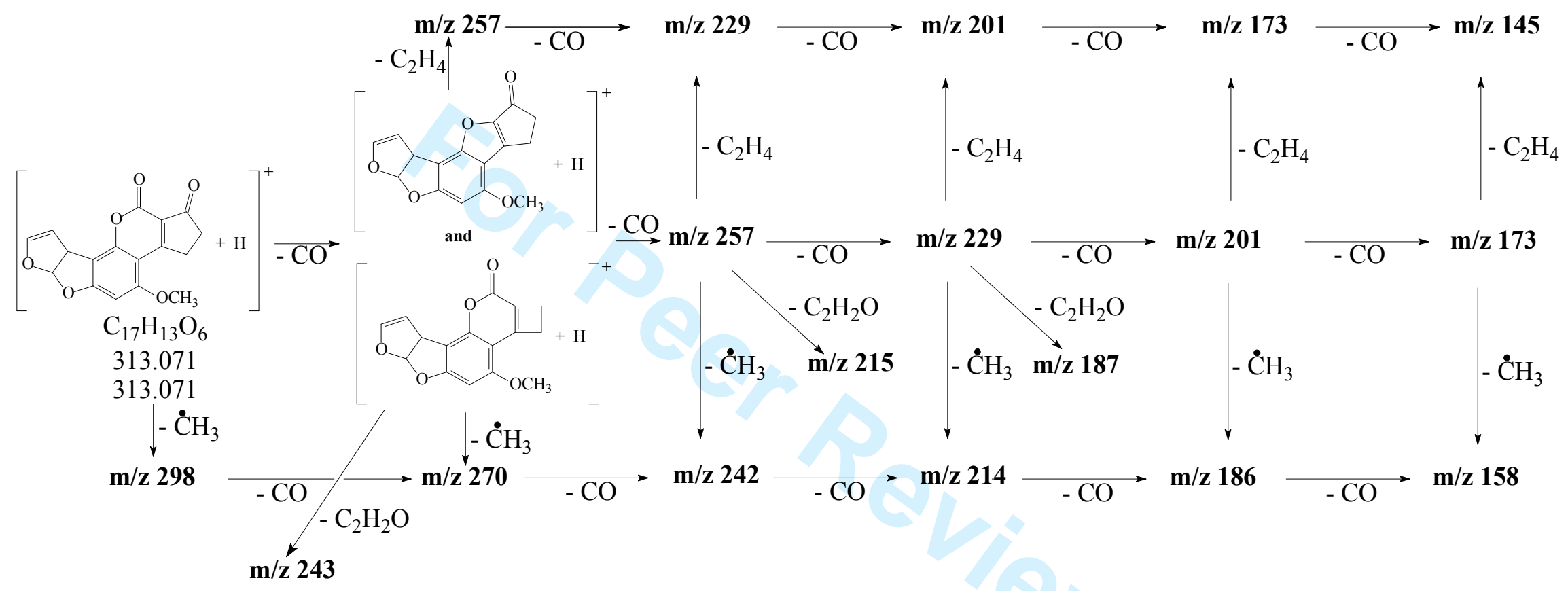


Scheme 3.

Aflatoxin B2 protonated at $\mathrm{O}(7)$ oxygen atom
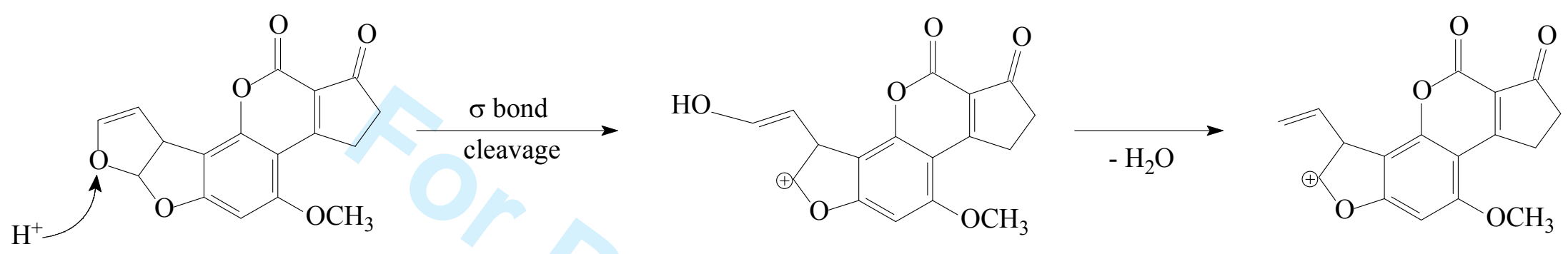
Scheme 4.

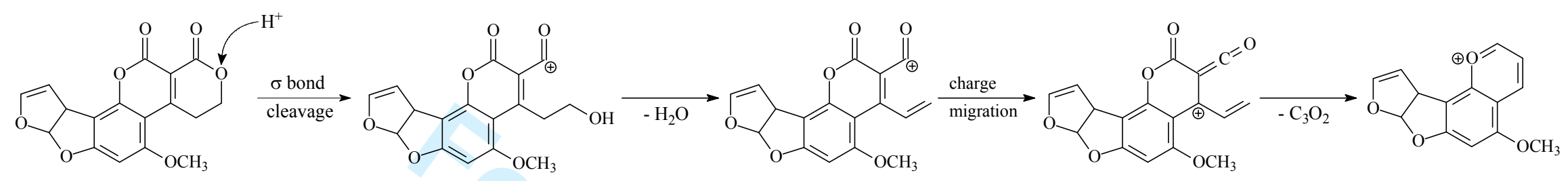


Fig. 1.

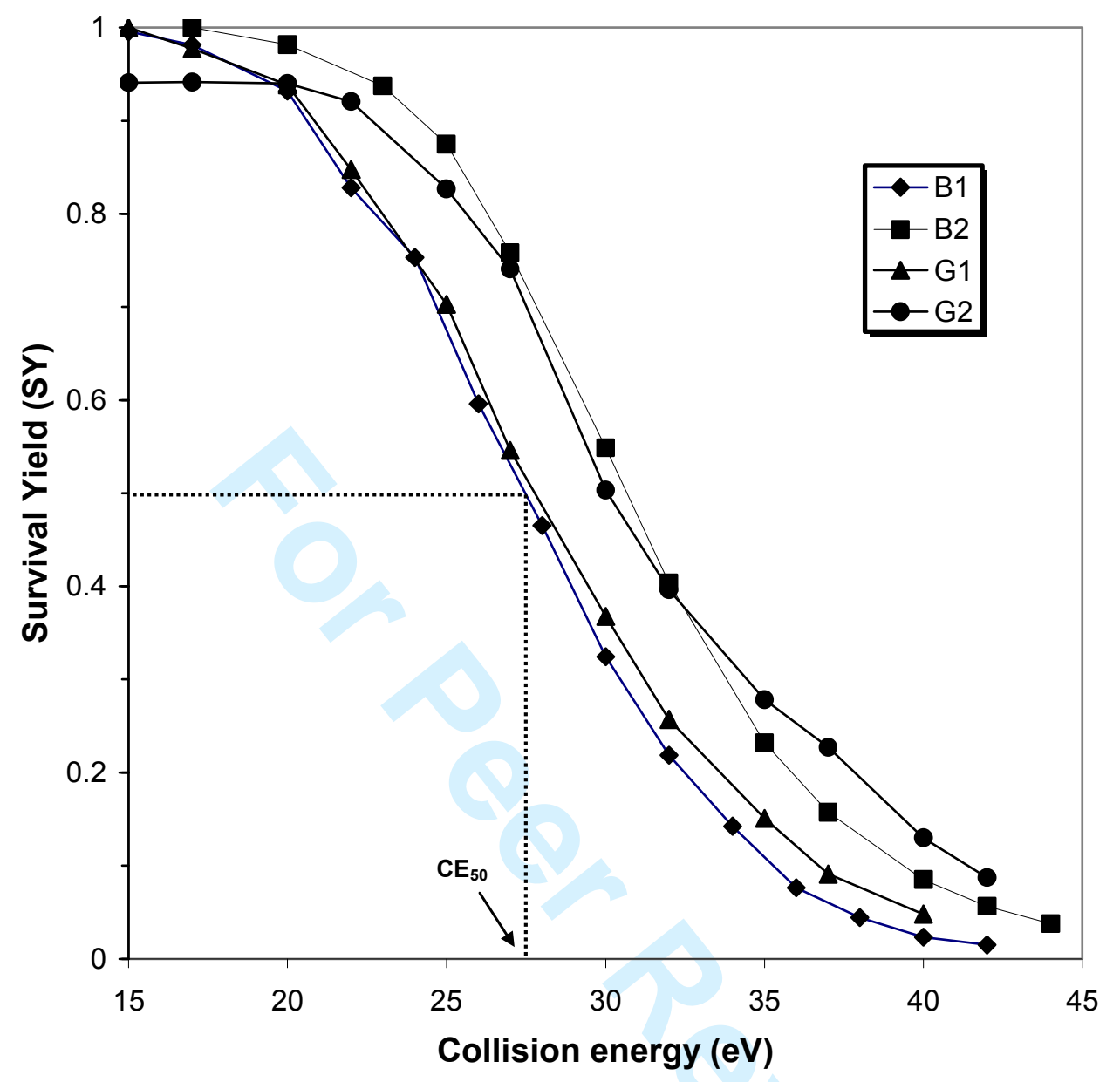

36

37

38

39

40

41

42

43

44

45

46

47

48

49

50

51

52

53

54

55

56

57

58

59

60 
Fig. 2.

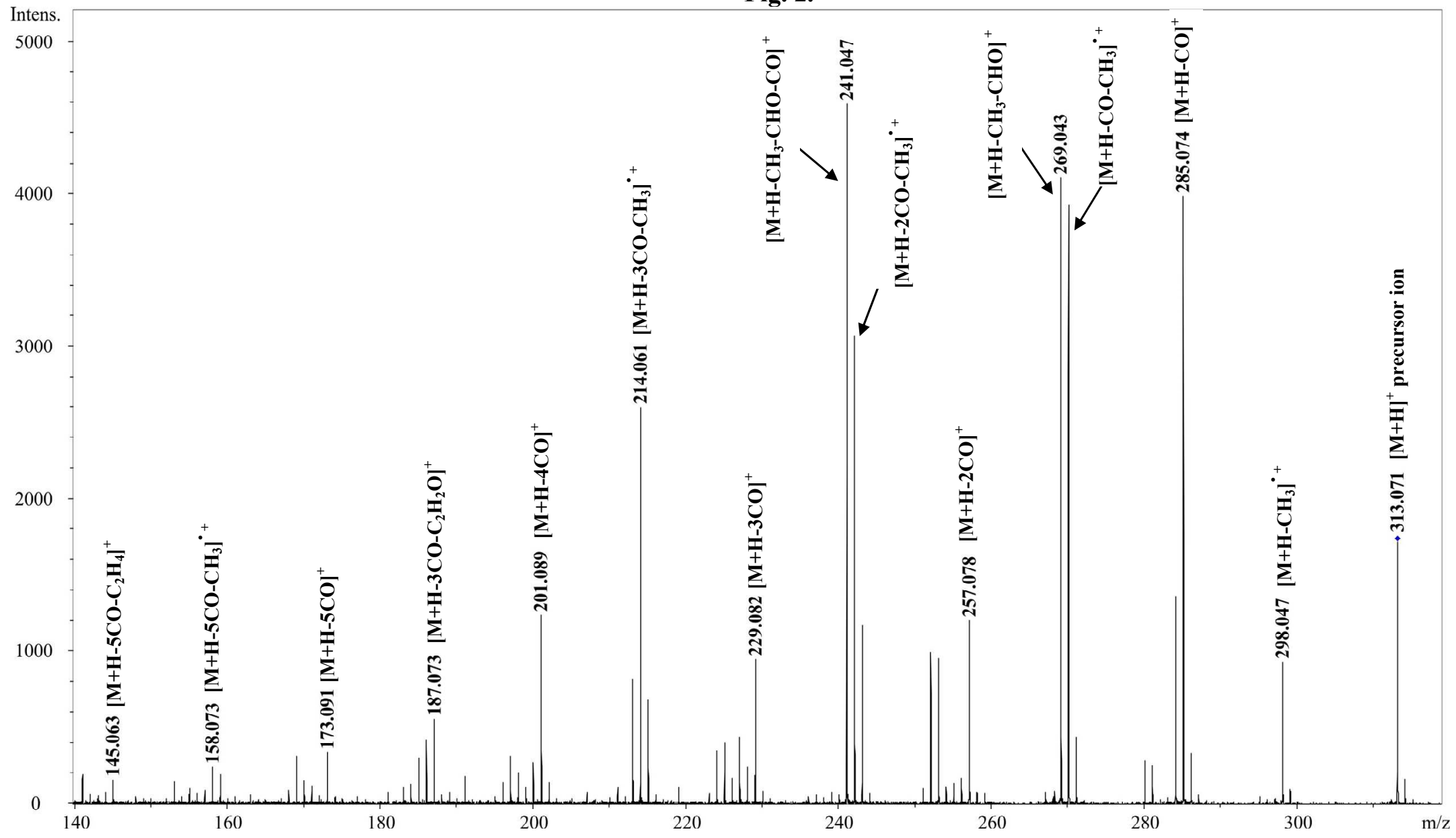


Fig. 3.
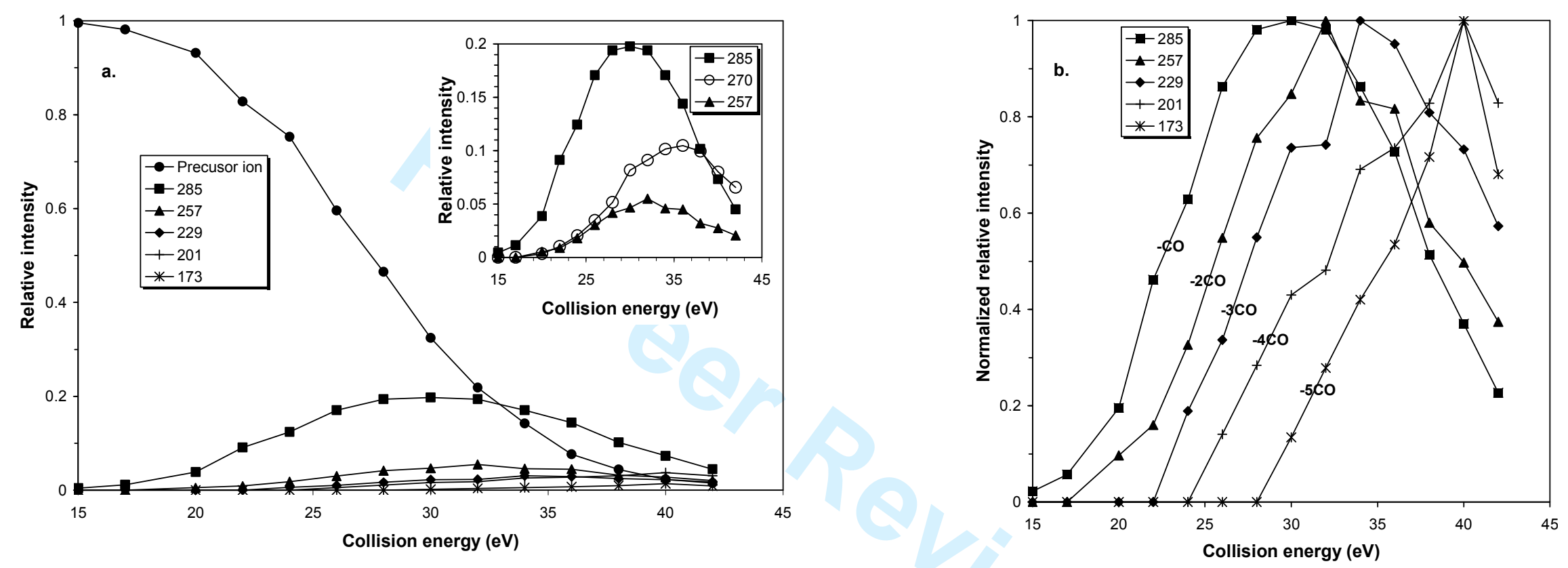
Fig. 4.

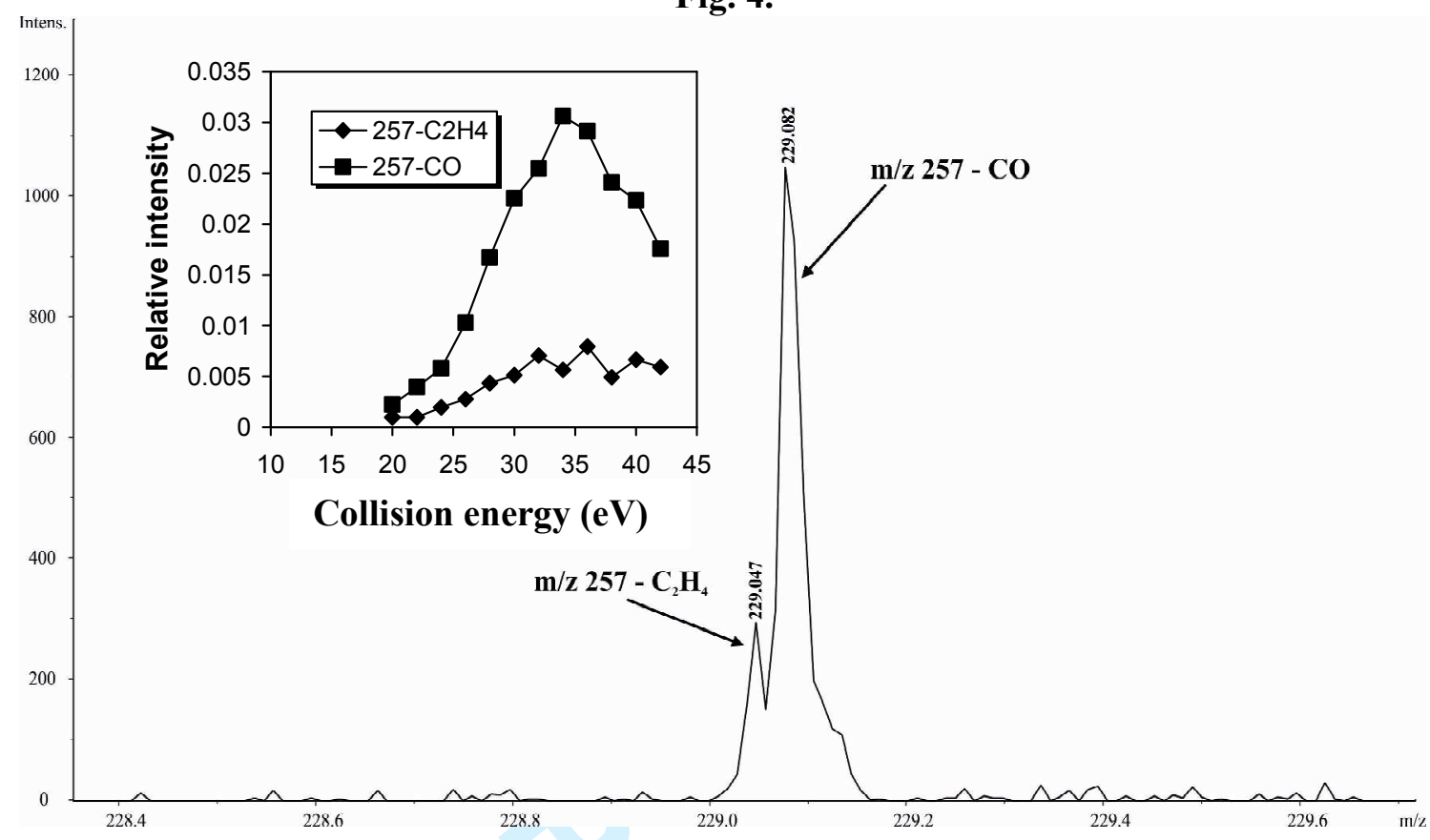


Fig. 5.

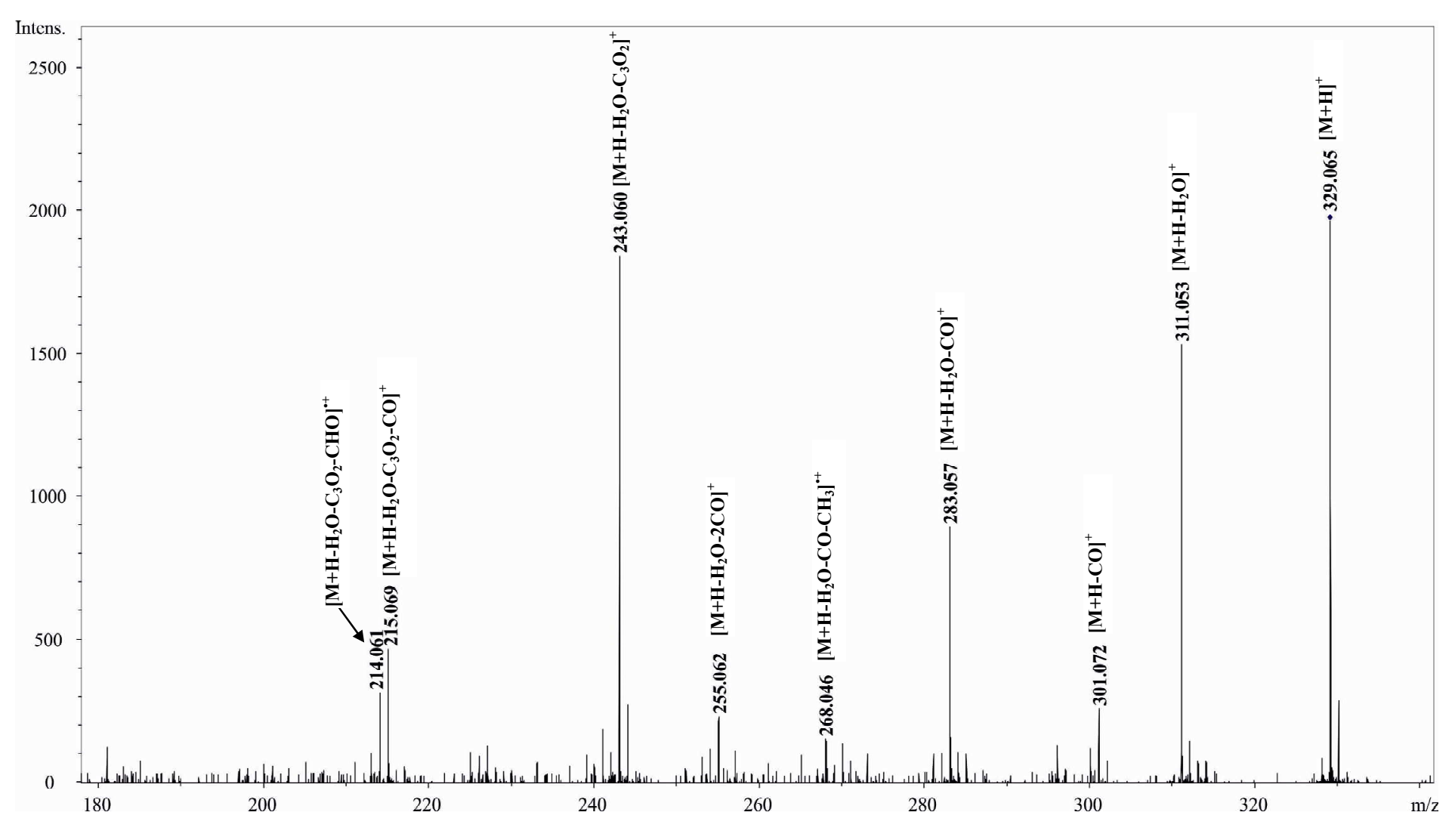


Fig. 6.

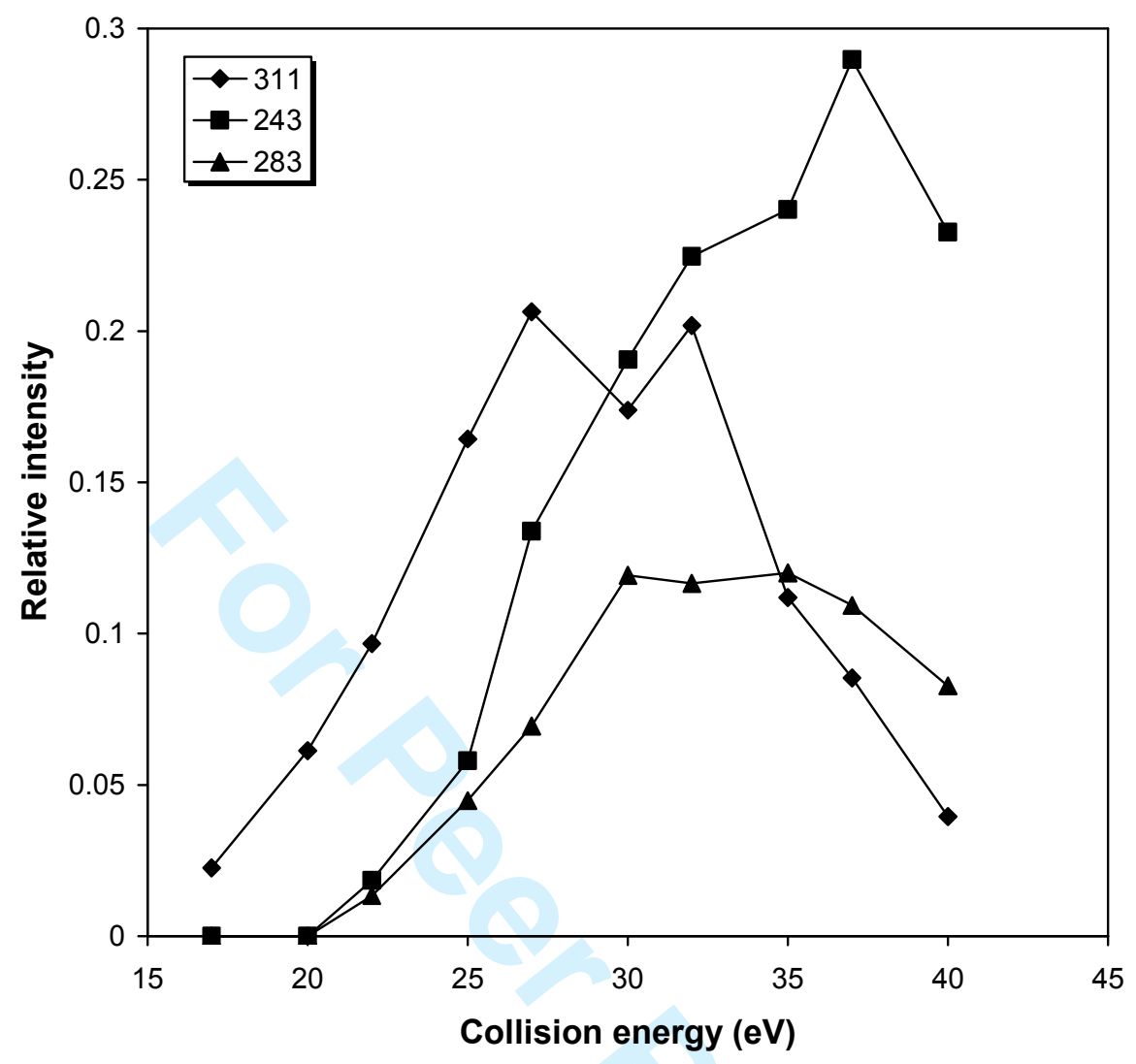

34

35

36

37

38

39

40

41

42

43

44

45

46

47

48

49

50

51

52

53

54

55

56

57

58

59

60

http://mc.manusciriptcentral.com/rcm 